\title{
Effect of nanoclay on thermomechanical properties of epoxy/glass fibre composites
}

\author{
T. D. Ngo, Q. T. Nguyen, T. P. Nguyen and P. Tran ${ }^{*}$ \\ Infrastructure Engineering Faculty \\ The University of Melbourne, Victoria, Australia
}

Corresponding author: Dr Phuong Tran, phuong.tran@unimelb.edu.au, Tel: +61 468316863

\begin{abstract}
This study investigates the effects of nanoclay on the mechanical properties and fire performance of epoxy/glass fibre composites. The cone calorimeter test in a horizontal configuration is used as the bench-scale test to determine the heat and smoke production from samples with nanoclay contents ranging from $1 \mathrm{wt} . \%$ to $5 \mathrm{wt} . \%$. All the samples are produced by a vacuum infusion process. Pristine nanoclay is treated with an organic surfactant before adding it to the mixture in the designed procedure. The results show that a low percentage of less than $3 \mathrm{wt} . \%$ nanoclay produces a scattered nanoparticle dispersion and, therefore, is insufficient for char formation. The combustion of the organic surfactant in nanoclay and the polymeric resin also outperform the effect of nanoclay at this level. At $5 \mathrm{wt} \%$ nanoclay replacement, a delay of 7 seconds in heat release rate, $45 \%$ lower peak of heat release rate, $15 \%$ lower total heat release, and $15 \%$ lower smoke production rate are observed. Scanning electron microscopy (SEM) images of the samples with varied organophilic clay concentration taken before and after the cone tests are presented to reveal the distribution of clay nanoparticles in the composite samples. The mechanical properties such as ultimate strength, Young's modulus of the nanoclay-enhanced composite are acquired from standard tensile test to determine the influences of clay content.
\end{abstract}

Keywords: Nanoclay, Fire performance, Nanocomposite, Building materials, Building façades, Thermo-mechanical.

\section{INTRODUCTION}

Composites made from glass fibre reinforcement and polymeric matrix offer excellent alternatives of strong, light-weight, flexible, cost-effective and sustainable materials when compared with conventional materials used in building construction, especially modern façade systems (such as aluminium and steel) [1-4]. One of the major issues that hinder the extensive use of composite structures in high-rise building is their fire resistance performance. While glass fibre reinforced polymer (GFRP) composites possess the required strengths with low embodied energy, the main obstacle preventing application of GFRP in building construction is its poor performance when exposed to fire hazards. FRPs used in infrastructure applications are susceptible to fire exposure owing to its thermo-mechanical softening [5-8] mechanisms. Other main contributor to this inferior fire performance is the highly flammable resin, and the glass fibre reinforcement exacerbates the flammability of the composite due to a "candle-wick effect" [9-11]. Significant efforts have been devoted to develop better material systems and composite manufacturing technology to satisfy various 
building construction safety codes whilst maintaining architectural aesthetic appeal. For sandwich structures used in façade systems (see Figure 1), the foam core can be designed especially for high flame retardancy; however, the composite layers are still sensitive to fire, and thus require critical improvement to pass fire performance requirements in the built environment.

\section{Figure 1}

For polymeric composites, apart from the enhancing effect on mechanical properties [12-17], nanoclay has been considered as an alternative to conventional flame retardants (FRs) such as metal hydroxides and halogenated FRs, especially as metal hydroxides only show significant improvement at high replacement levels [18-20]. These high replacement levels are used to meet the fire safety standards of construction materials; however, high replacement levels of metal hydroxides in composites dramatically weaken their mechanical properties due to material mismatch-induced localised failures. On the other hand, Halogenated FRs containing toxic compounds, which raise concerns on the environmental and public health safety, are restricted or even forbidden in many countries. Most available research on the flame retardant effect of nanoclay has only focused on the polymeric matrix, especially thermoplastic resins (Beyer [21], Dabrowski et al [22], Gilman [23], Gilman et al [24], Gilman et al [25], Liu et al [26], Morgan [27], Morgan et al [28], Shi et al [29]). For example, Huang et al. [19] investigated the effect of nanoclay on the flame retardancy of poly(methyl methacrylate) (PMMA). Nanoclay was modified by undergoing a cation exchange reaction to achieve sodium montmorillonite (MMT). The flame retardant characteristics of the samples were tested using a cone calorimeter in a horizontal orientation with a heat flux of $35 \mathrm{~kW} / \mathrm{m}^{2}$. At $5 \mathrm{wt} . \%$ of nanoclay introduced into the PMMA, the peak of heat release rate reduced by $18 \%$ to $406 \mathrm{~kW} / \mathrm{m}^{2}$. There is also a reduction of total heat release from the PMMA/nanoclay sample from $67 \mathrm{MJ} / \mathrm{m}^{2}$ to $65 \mathrm{MJ} / \mathrm{m}^{2}$. It was observed that nanoclay promoted the formation of char residues during the burning process, with a thin layer of char found after the cone calorimeter test. The pure PMMA sample was burnt with almost no residue at the end of the combustion. However, this enhancement effect of nanoclay was not effective because nanoclay as an inorganic filler will exhibit low interaction with the organic polymer matrix. Thirumal et al. [20] added organically modified nanoclay (organoclay) 1-10 wt.\% to polyurethane foam and tested the flame retardant properties with a limiting oxygen index (LOI) test and flame spread rate measurement. Methyl tallow-bis-2hydroxyethyl quaternary ammonium was the organic agent used to modify the nanoclay. The purpose of organic modification was to improve the organophilicity of the filler surface, and thus the dispersion of the filler in the organic polymer matrix. The addition of organoclay improved the flame retardancy of polyurethane foam when the loading content was up to $5 \mathrm{wt} . \%$. Higher loading of organoclay (over $5 \mathrm{wt} . \%$ ) in the polymer resulted in higher flammability owing to the agglomeration of organoclay. In another research, organoclay at low loading (less than $5 \mathrm{wt} . \%$ ) also promoted significant improvements in the flame retardancy of polyamide [18].

Compared to the combustion of the polymeric resin, that of the glass fibre reinforced composite from the same polymer is often more severe as the glass fibre reinforcement possesses a higher thermal conductivity and acts as the "candlewick" to promote the combustion of the resin, which is known as "candlewick effect". Apart from the "candlewick effect", the integration of nanoclay into glass fibre composites also affects the liquid moulding process such as resin infusion because this solid filler may alter the physical properties of the liquid resin. In this study, the effect of organoclay with loading from $1 \mathrm{wt} . \%$ 
to $5 \mathrm{wt} . \%$ on the fire performance of glass fibre/thermosetting (epoxy) composites is investigated. Nanoclay placements of higher than $5 \%$ makes the mixed resin too viscous to be infused through the designed layers of glass fabrics, thus the loading of nanoclay is selected to be not more than $5 \%$ in this study [29]. Glass fibre/epoxy composite is selected according to the appropriateness to the application in modern façade systems with a high balance between product quality and the manufacturing process. Apart from mechanical mixing, sonication energy is used to improve the dispersion of organoclay into the resin before fabrication. Fire performance of the composites will be studied using the cone calorimeter method, which is one of the most effective bench-scale tests for heat release rate and smoke production of polymer-based materials. Organoclay will be added to the resin at three different replacement levels and the corresponding samples will be fabricated by the vacuum infusion process.

\section{EXPERIMENTAL WORK}

\subsection{Materials}

Epoxy (Kinetix R118) obtained from ATL Composites is used as the resin. The Kinetix contains bisphenol A (more than $60 \%$ by weight) and bisphenol $\mathrm{F}$, and is diluted by 1,6 hexanediglycidyl ether and aliphatic glycidylether C12-C14 alcohols. The slow hardener Kinetix H120 produced by ATL Composites is selected to cure at room temperature. The gelling time of the resin falls into the range of $40-60$ minutes at $25^{\circ} \mathrm{C}$. Viscosity of Kinetix and mixture of the resin with $\mathrm{H} 120$ at $25^{\circ} \mathrm{C}$ are $375 \mathrm{mPa} . \mathrm{s}$ and $200 \mathrm{mPa}$.s, respectively.

The reinforcement is composed of six layers $\left(0^{\circ} / 90^{\circ} / 0^{\circ} / 90^{\circ} / 0^{\circ} / 90^{\circ}\right)$ of $410 \mathrm{gsm}$ biaxial E-glass fabric CK0400 (ATL Composites). The $0^{\circ}$ fabric layer weighs $236 \mathrm{gsm}$, while the weight of the $90^{\circ}$ layer is $174 \mathrm{gsm}$. Biaxial fabrics are chosen over woven ones as they work efficiently with this particular infusion process, especially with the presence of nanoparticles, which induces considerable viscosity to the resin.

Nanoclay 682640 from Sigma-Aldrich Australia, which is used in this work, was manufactured especially for flame retardant purposes. Nanoclay contains $35-40 \mathrm{wt}$ \% of the organic modified agent. The clay nanoplates are $200-300 \mathrm{~nm}$ in lateral dimension and $1 \mathrm{~nm}$ in thickness. After surface treatment, the clay has an average particle size of $10-11 \mu \mathrm{m}$.

\subsection{Clay dispersion}

The dispersion of the clay into the epoxy is illustrated in Figure 2. The Kinetix is degassed for 30 minutes at first, followed by a gradual process of adding nanoclay into the resin. The material compositions of four samples with varying nanoclay contents are presented in Table 1. An overhead mechanical mixer with a speed of $500 \mathrm{rpm}$ is used to mix the resin for 30 minutes. It is observed that the mixtures were in a slurry-like form. There is, however, a gradual deposit of nanoclay particles in the mixture to form a noticeably separate layer at the bottom after being left for 30 minutes.

\section{Table 1}

To ensure good dispersion of nanoclay into the resin, the slurry-like mixture is sonicated in the bath sonicator in two steps: degassing for 10 minutes, and then sonicating for 30 minutes. The degassing step has proven necessary as it helps to reduce the degassing time prior to the infusion process. The sonicator is set to operate at a frequency of $40 \mathrm{kHz}$.

Figure 2

To ensure the effectiveness of sonication, the mixtures are divided into portions of less than $100 \mathrm{ml}$. The samples after sonication appeared to be a "milky liquid" and no separation was 
observed after 30 minutes. The control sample without nanoclay is treated using the same procedure to ensure consistency.

\subsection{Composite fabrication}

The composite laminates are fabricated using a vacuum infusion process, where six layers of glass fibre fabric are cut to a size of $380 \mathrm{~mm}$ x $540 \mathrm{~mm}$ and are stacked together. A hardener is added to the treated/control resin with a weight ratio of 1:4. Mixtures are then degassed for 30 minutes at $98 \%$ vacuum level in the resin trap.

The stack of reinforcement fabric is laid in the mould and infused with Enka channel/distribution media/peel-ply. The infusion proceeds at $98 \%$ vacuum level, and the leak level is limited to $2 \mathrm{mbar} / 5$ minutes. The vacuum is turned off four hours after the infusion process and the samples are demoulded after ten hours. All the samples are cured at room temperature and post-cured at $60{ }^{\circ} \mathrm{C}$ for five hours.

\subsection{Materials characterisation techniques}

Elemental analysis of the samples is carried out using a Phillips XL30 EDS scanning electron microscope (SEM). This is a high vacuum SEM equipped with an Oxford Instruments ISIS energy-dispersive X-ray spectrometer (EDS) X-ray microanalysis system. An electron beam of $10 \mathrm{kV}$ is used for each measurement, and fluorescent $\mathrm{X}$-rays are collected from the samples by the EDS. The samples are cut from the post-cured panel and treated with a Dynavac SC100 magnetron sputter coater to achieve a coating layer of gold over the surface in order to enhance the measurements.

Fire retardancy of the composite is evaluated using cone calorimeter tests conducted at Victoria University's Centre for Environmental Safety and Risk Engineering (CESARE) laboratories, in accordance with ISO 5660-1 (Figure 3). The samples are tested in a horizontal orientation. They are cut from post-cured panels to the size of $100 \times 100 \times 3 \mathrm{~mm}$ and are exposed to a $50 \mathrm{~kW} / \mathrm{m}^{2}$ radiant cone. Samples of each composition are tested with $\pm 10 \%$ reproducibility of at least three independent runs. Thermal resistant wool is utilised to prevent heat loss from samples to the stainless steel holder. The thickness of the wool is designed to ensure that the distance between the upper surface of the sample and the pilot igniter equals $25 \mathrm{~mm}$. Heavy aluminium foils are carefully wrapped over the lower surface and vertical sides of the samples so that no liquid resin can leak out of the combustion zone. In all tests, the pilot igniters are removed immediately after the continuous flame occurs.

\section{Figure 3}

The field emission SEM (Phillips XL30) is used to study the distribution of nanoclay particles over the surface of the infused panel. Samples are also coated with gold in the Dynavac SC100 magnetron sputter coater for 10 minutes, and scanned in the SEM at an operating voltage of $10 \mathrm{kV}$.

\section{FIRE PERFORMANCES: RESULTS AND DISCUSSIONS}

\subsection{Microanalysis of nanoclay and GFRP samples}

Microanalysis conducted with the SEM-EDS analyser provides the elemental details of the phases in the samples. Figure 4a shows the image of sample E3 at 3000x magnification. Three spectrums are collected at different locations, which represent the epoxy resin (spectrum 1, Figure 4b), large tactoids (spectrum 2, Figure 4c), and smaller particles (spectrum 3, Figure 4d). Element Au (gold) is shown in all the spectrums because the sample is coated with a gold layer in the sputter prior to the tests. 


\section{Figure 4}

The appearance of only element $\mathrm{C}$ (carbon) and $\mathrm{O}$ (oxygen), apart from element $\mathrm{Au}$, in spectrum 1 shows a typical point of the resin with an organic composition. Spectrums 2 and 3 show similar elements present, such as $\mathrm{Si}$ (silicon), $\mathrm{Ca}$ (calcium), Al (aluminium) and $\mathrm{Mg}$ (Magnesium). These results further confirm the appearance of MMT crystals in the composite structure.

\subsection{Heat release rate}

In cone calorimeter tests, heat release rate (HRR) is determined based on the consumption of oxygen level. HRR reflects the contribution of a material to fire, along with the time. As can be seen from Figure 5a, HRR curves of all samples have a bell-like shape. Sample E0 (with no nanoclay) possesses a stiff HRR curve before reaching a peak HRR (PHRR) at $818 \mathrm{~kW} / \mathrm{m}^{2}$ due to the severe burning of epoxy in the laminate. The introduction of nanoclay in the laminate (E1-E5) helps to reduce the PHRR to only 65-70\% that of the E0 sample. It can also be clearly observed that all samples containing nanoclay have earlier starting points of HRR curves owing to the organic surfactant in nanoclay. In this study, the pristine inorganic nanoclay was modified by an organic surfactant (35-40 wt.\%), which is flammable. It is interesting to note that sample E3 (3 wt.\% of nanoclay) has a higher PHRR than that of sample E1 (1 wt.\% of nanoclay). The time ( $\left.T_{p}\right)$ to achieve PHRR of sample E3 is $5 \mathrm{~s}$ earlier than that of sample E1 (Table 2).

\section{Table 2}

This can be explained by the fact that the increase of nanoclay concentration enhances the viscosity of the resin mixture, thus making the laminate thicker under the same fabrication vacuum level. On the other hand, at a nanoclay placement of $5 \mathrm{wt} . \%$, sample E5 obtains excellent fire performance with the lowest PHRR (45\% lower than that of E0) and $T_{p}$ is delayed until $71 \mathrm{~s}$. In this case, a higher percentage of nanoclay is essential to form a char layer during the burning process, which acts like a barrier lowering the combustion of the organic surfactant as well as the epoxy.

\section{Figure 5}

Figure $5 \mathrm{~b}$ presents mass changes of all the samples during the cone calorimeter tests. As expected, sample E0 has the lowest residue of $60.3 \%$ of the initial mass before testing which further proves that sample E0 without nanoclay burns more severely than others. Sample E1 and E3 have similar mass of residue (61.7\% and $61.3 \%$, respectively), which coincides with the HRR curves. Sample E5 has the highest final mass (63.4\%), which is firm evidence of char formation at this loading content of nanoclay. This low conductive char layer helps to isolate the heat from the flame and, therefore, reduces further combustion. In this study, a ratio of PHRR to $T_{p}$ is calculated for each test to evaluate the potential of flame spread, whereby a high ratio of PHRR to $T_{p}$ reflects a high risk of fast flame spread. Table 2 summarises the values of PHRR, $T_{p}$ and their ratios for all samples, showing that all samples $\mathrm{E} 1-\mathrm{E} 5$ have lower PHRR/T $\mathrm{T}$ ratios than E0. When the percentage of nanoclay is $5 \%$, as in the case of sample E5, the PHRR/T ratio of 7.50 is the lowest among the samples.

\subsection{Total heat release (THR) and heat of combustion}

Figure 6a presents the total heat release (THR) curves and heat of combustion of the samples. There is a reduction trend of THR with the increase of nanoclay content from $1 \mathrm{wt} . \%$ to 5 wt. \%. In fact, THR of sample E5 is $15 \%$ lower than THR of the baseline sample E0. These figures also show that although sample E3 has a higher PHRR/T ratio, the slightly lower THR indicates that nanoclay still exhibits its improvement effect on the laminate. A similar 
trend is observed with heat of combustion. Heat of combustion is measured per unit weight of the samples, which theoretically reflects the improvement effect of nanoclay on the laminate's flame retardancy. Heat of combustion is not, however, commonly used as THR measure the fire performance of construction materials in building standards and codes.

\section{Figure 6}

If THR is determined per area of the burning sample, heat of combustion is calculated according to the mass unit of the sample. Heat of combustion is not affected by other parameters, thus reflects the effect of nanoclay loading on flammability more accurately than THR. However, THR is commonly used in practice and THR is used to calculate the fire performance of construction materials in buildings.

The laminate thickness and resin infusion time are also indicated in Table 3. The laminate thickness was measured at five different points in the laminate after curing, while the resin infusion time is the required time for the resin to flow through the glass fibre layers. The infusion time is calculated as follow:

$$
t=\frac{L}{v},
$$

where $t$ is the infusion time (s), $L$ is the length of the glass fibre layers $(\mathrm{m})$, and $v$ is the velocity of the resin travelling through the length of the reinforcement layers $(\mathrm{m} / \mathrm{s})$. The value of $v$ is calculated according to Darcy's law (Equation 2), as follows:

$$
v=-\frac{k \cdot \nabla P}{\mu \cdot n}
$$

where $k$ is the cross-sectional area for the resin to flow $\left(\mathrm{m}^{2}\right), \nabla P$ is the pressure gradient vector $(\mathrm{Pa} / \mathrm{m}), \mu$ is the viscosity of the resin (Pa.s) and $n$ is the porosity of the glass fibre stack.

\section{Table 3}

According to Equation 1 and Equation 2, while all other parameters are maintained unchanged, the increase in viscosity of the resin as the result of additional nanoclay is the reason for the longer infusion time. As expected, the infusion time of sample E1 is longer than that of sample E0. On the other hand, infusion times of sample E3 and E5 are double that of sample E1, which clearly indicates the rapid increase of resin viscosity at high loading of nanoclay ( 3 wt.\% and 5 wt.\%). This explains the high PHRR of sample E3, where char formation is not sufficient to overcome the high proportion of epoxy resin in the laminate.

\subsection{Smoke release}

Besides the heat released from materials during a fire incident, smoke production is another important characteristic and the main cause of death in a fire event, especially in residential fires. Polymeric resin in the composite triggers a higher risk due to its pyrolysis reaction. The pyrolysis reaction of polymeric resins only requires sufficient heat and then occurs even in an oxygen deficient atmosphere:

$$
r=\left(\frac{\rho}{\rho_{0}}\right)^{n} A e^{-\frac{E}{R T}}
$$

where $r$ is the reaction rate $\left(s^{-1}\right), \rho$ is the density $\left(\mathrm{kg} / \mathrm{m}^{3}\right), \rho_{0}$ is the initial density $\left(\mathrm{kg} / \mathrm{m}^{3}\right), A$ is the pre-exponential factor $(1 / \mathrm{s}), E$ is the activation energy $(\mathrm{kJ} / \mathrm{kmol}), R$ is the Stefan-Boltzmann constant $\left(W / m^{2} K^{4}\right), T$ is the temperature of the material $(K)$, and $n$ is the reaction order." 
In addition, incomplete combustion of composite laminates also leads to the production of carbon monoxide, which is known as a toxic agent to humans. High exposure to carbon monoxide smoke could lead to serious organ damage, even death. Smoke production properties, such as smoke production rate (SPR), total smoke production (TSP), carbon monoxide yield $\left(\mathrm{CO}_{\mathrm{y}}\right)$ and carbon dioxide yield $\left(\mathrm{CO}_{2 \mathrm{y}}\right)$, of all the samples exposed to a heat flux of $50 \mathrm{~kW} / \mathrm{m}^{2}$ are demonstrated in Figure $6 \mathrm{~b}$, Table 2 and Table 3. SPR is calculated as the product of the specific extinction area and mass loss rate of the samples. Figure 6b shows a peak of SPR for sample E1 that is $15 \%$ higher than E3 and E5, although all samples with nanoclay (E1-E5) obtain a lower peak of SPR than the baseline sample E0. TSPs, another parameter to evaluating fire hazard through smoke suppression, of sample E1 and E5 are relatively lower than that of the baseline sample E0. These results show that nanoclay contributes to lowering the smoke produced from burning laminates significantly at $5 \% \mathrm{wt}$. replacement. This is a clear advantage of using nanoclay as a flame retardant compared to the previously mentioned metal hydroxide, which often produces more released smoke. On the other hand, the high TSP $10.01 \mathrm{~m}^{2}$ of sample $\mathrm{E} 3$ again proves the burning of the organic surfactant in nanoclay. $\mathrm{CO}_{\mathrm{y}}$ and $\mathrm{CO}_{2 \mathrm{y}}$ are often considered to evaluate the toxicity of the smoke release from the burning process as smoke suppression relates to both suffocation and inhalation of toxic gases of human on site. When the concentration of nanoclay increases from $0 \mathrm{wt} . \%$ to 5 wt. \%, $\mathrm{CO}_{2 \mathrm{y}}$ decreases while $\mathrm{CO}_{\mathrm{y}}$ increases. $\mathrm{CO}_{\mathrm{y}}$ and $\mathrm{CO}_{2 \mathrm{y}}$ have a close relationship with the formation of char during the burning process, which will be discussed further in section 3.5. Charring materials with more residues often possesses higher $\mathrm{CO}_{\mathrm{y}}$ and lower $\mathrm{CO}_{2 \mathrm{y}}$ as non-charring materials burn away more completely and thus, obtain lower $\mathrm{CO}_{\mathrm{y}}$ and higher $\mathrm{CO}_{2 \mathrm{y}}[30]$.

\subsection{Char formation and nanoclay distribution}

Figure 7 presents images of the control sample (E0) and other samples with nanoclay additives (E1, E3, E5), before and after the cone test at heat flux of $50 \mathrm{~kW} / \mathrm{m}^{2}$. As clearly seen from this figure, the addition of clay nanoparticles up to $5 \mathrm{wt} \%$ does not affect the colour and translucence of the composite samples. Sample E0 and E1 are burnt and the glass fibres are exposed to the heat, with very little char formation observed after the tests. Sample E3 with $3 \mathrm{wt}$ \% nanoclay is observed to have approximately half of its surface covered with a thin layer of char, while a thicker layer of char is found to cover the whole surface of sample E5. Together with results from PHRR (Figure 5), this confirms the role of the newly formed char layer on the fire retardancy of the laminate and that $5 \mathrm{wt} . \%$ of nanoclay is the minimum loading to achieve a sufficient char layer.

\section{Figure 7}

This observation is elaborated by SEM images of the samples taken at different magnifications of 200x, 800x and 3000x, as shown in Figure 8. With low percentages of nanoclay (1 wt.\%), images of sample E1 show a very scattered distribution of clay nanoparticles. Agglomeration also takes place with a diameter of nanoclay less than $25 \mu \mathrm{m}$. These two factors, plus the presence of an organic surfactant, lead to the increase in combustion of the composite sample. As a result, both the heat and smoke released from sample E1 are higher than those obtained from the control sample E0.

\section{Figure 8}

The higher amount of nanoclay in E3 clearly leads to more formation of char. However, the agglomeration of $3 \mathrm{wt} . \%$ nanoclay in E3, as visualised in the Figure 8, produces considerably large clay aggregates with sizes of up to $50 \mu \mathrm{m}$. This clay aggregation deters the 
effectiveness of nanoclay in improving the flame retardancy of the composite samples. On the other hand, sample E5 achieves good distribution of clay, with small particles of less than $10 \mu \mathrm{m}$. This creates a network of clay nanoparticles on the surface and contributes to the formation of a thick char layer. This newly formed char layer plays a key role in lowering the heat released as well smoke production from the laminate. It is important to note that not only increasing the amount of nanoclay, but also minimising agglomeration and optimising clay nanoparticle distribution, is equally important to improve the flame retardancy of epoxy composites.

\section{INFLUENCES OF NANOCLAY ON MECHANICAL PROPERTIES}

One of the major concern when using nanoclay as retardant in GFRP composite is its influences in the mechanical properties of the composite. It is, therefore, important to determine the influence of nanoclay placement percentage on mechanical properties of the GFRP composite. It is important to note that in this work, we just focus on the mechanical performance of the composite in the normal laboratory conditions and their behavior during the fire event is beyond the scope of this work. It is also reasonable to assume that during the fire event, the heat and smoke productions are the most detrimental effects on the occupant's lives while the mechanical properties are critical in the regular conditions. In this study, tensile strength tests are performed according to the European Standard EN ISO 527-4, which defines the test conditions for isotropic and orthotropic fiber-reinforced composites. Other mechanical properties such as creep rupture and durability will be tested further and are beyond the scope of this study. The specimens were cut from the GFRP panels as rectangular strips without end tabs as stipulated in the standard as shown in Figure 9. Due to the brittle nature of the FRP composite, especially at the edges, direct contacts of extensometers could create considerable damages to the samples, leading to bias deformation and fracture during the test. Instead, the 5960 INSTRON Testing Systems, which has been used for these tensile tests, are fully calibrated to obtain the accurate displacements. As samples are rectangular without particular gauge sections, the measured displacements by the INSTRON are reasonably used for the strain analysis.

\section{Figure 9}

The total length of each specimen is $250 \mathrm{~mm}$ and the effective length is $150 \mathrm{~mm}$ with negligible variation in the range of $\pm 4 \%$. The applied test speed (crosshead speed) is 2 $\mathrm{mm} / \mathrm{min}$ according to the EN ISO 527-4 standard for testing specimens to acquire its maximum tensile stress and elastic modulus. Four samples are tested for each level of nanoclay placements from $0 \%$ to $5 \%$ and the experimental results are given in the Figure 10 and Table 4.

\section{Table 4}

Figure 10 presents the testing evidences of the nanoclay-enhance GFRP composites. Stressstrain curves are summarised for different cases of clay content level as presented in the Figure 10. For each level of clay placement percentage, the results of tensile strength, maximum strain and elastic modulus are quite consistent with the mean value as well as standard deviations are given in the Table 4. For all the cases, tensile strength value ranges from $350 \mathrm{MPa}$ to $400 \mathrm{MPa}$ and the elastic modulus varies between $5.6 \mathrm{GPa}$ to $6.1 \mathrm{GPa}$. This is a noticeable increase in tensile strength and elastic modulus from $0 \mathrm{wt} . \%$ to $3 \mathrm{wt} . \%$ nanoclay placement cases, which indicate the positive effect of nanoclay on the mechanical properties of composite. At $5 \mathrm{wt} \% \%$ the obtained tensile strength and Young's modulus are still considerably higher than those of control case. 
The results are, however, not much different from the $5 \mathrm{wt}$.\% case. This phenomenon was also observed in literature $[29,31]$ and can be explained by the distribution of nanoclay platelets in the matrix and the surface interaction between the organic resin and the particles [31]. Additional nanoclay into the resin clearly contributes positive effects on the fire performance as discussed earlier as well as the mechanical strength of composite. This can be explained By increasing clay replacement percentage, the enhancement in thermomechanical properties of composite is also coupled with the higher viscosity of resin, which could in turn affects the distribution of clay particles in the composite as well as the infusion time. This suggests the existence of a threshold for clay content in the composite to achieve the optimum fire performance and mechanical properties.

\section{CONCLUSIONS}

The effect of nanoclay in GFRP was investigated with different replacement levels of organoclay. The composites were fabricated using a vacuum-assisted infusion process. Nanoclay loadings from $1 \mathrm{wt} . \%$ to $5 \mathrm{wt} . \%$ were observed to improve the fire performance of the epoxy laminates, with the $5 \mathrm{wt} . \%$ concentration producing the best results. At low levels of nanoclay replacement, combustion of the organic amine used as the surface modified agent and excess resin were observed to dominate the effect of the nanoclay. This led to a rise in peak heat release rate (PHRR) at $3 \mathrm{wt} \%$ (E3) levels. Mass loss curves, THR, and heat of combustion of sample E3 pointed to some enhancements with nanoclay inclusion. However, the formed layer of char was not sufficient to overcome the effects of combustion associated with an organic surfactant and excess resin. Sample E5 had the highest percentage of nanoclay (5 wt.\%) and had a well-distributed clay nanoparticle network, which evidently showed the best improvement in fire performance with the lowest THR, heat of combustion and SPR. Further work on higher fractions of nanoclay, as well as a detailed study on char formation with nanoclay presence, will be continued in order to understand the mechanisms of nanoclay in improving the flame retardancy of GFRPs. The mechanical properties of nanoclay-enhanced composite were investigated with tensile tests for samples with different clay contents. The results showed that the presence of clay in resin at these levels of placement percentage contributed to the enhancement in the overall mechanical properties. The result also suggested the existence of a threshold value of clay content, with which the optimum fire performance and mechanical properties could be achieved against the negative effects come from higher viscosity and infusion time.

\section{ACKNOWLEDGMENTS}

The authors would like to acknowledge Dr. Jinghan Lu for her assistance in fabricating the specimens; and Joe Abraham and Ariza Sharikin Abu Bakar for performing the cone calorimeter tests. The experimental work is conducted with financial support from ARC Linkage Grant LP110100429. The authors would also like to acknowledge the support from Permasteelisa Pty Ltd. 


\section{Figures \& Tables}

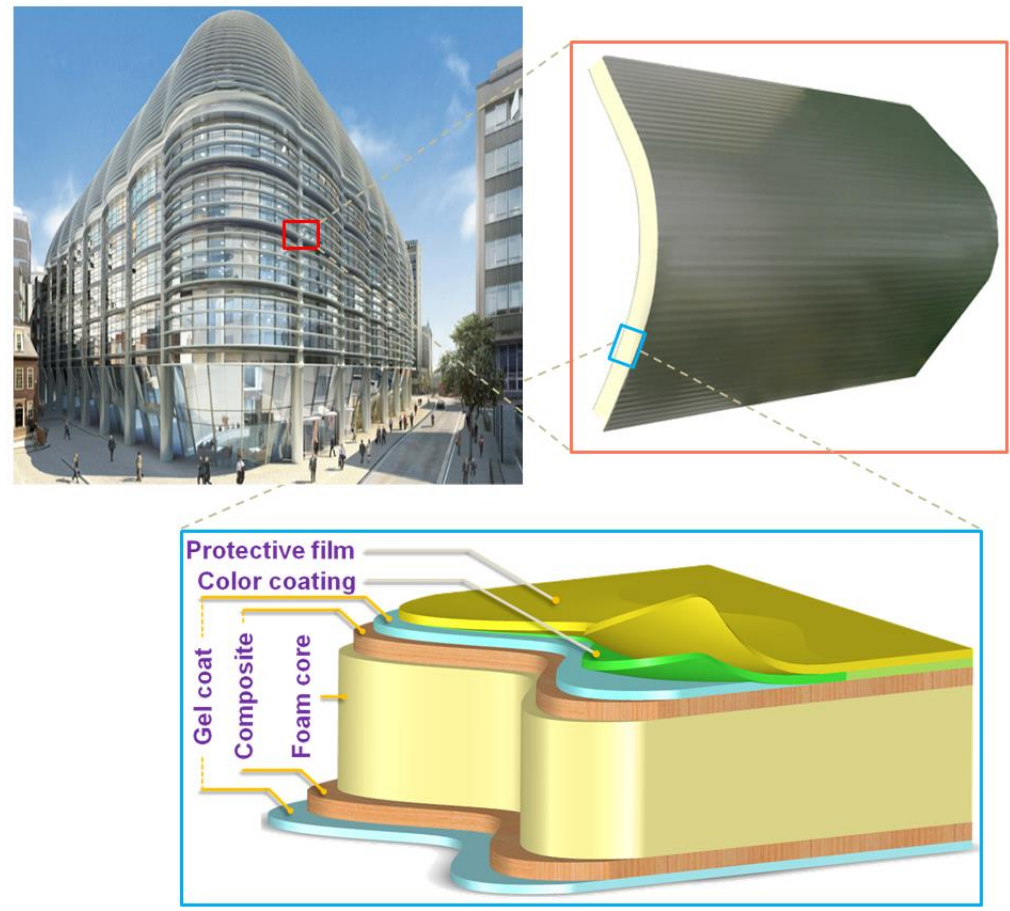

Figure 1. An example of a building façade made from sandwich structures 

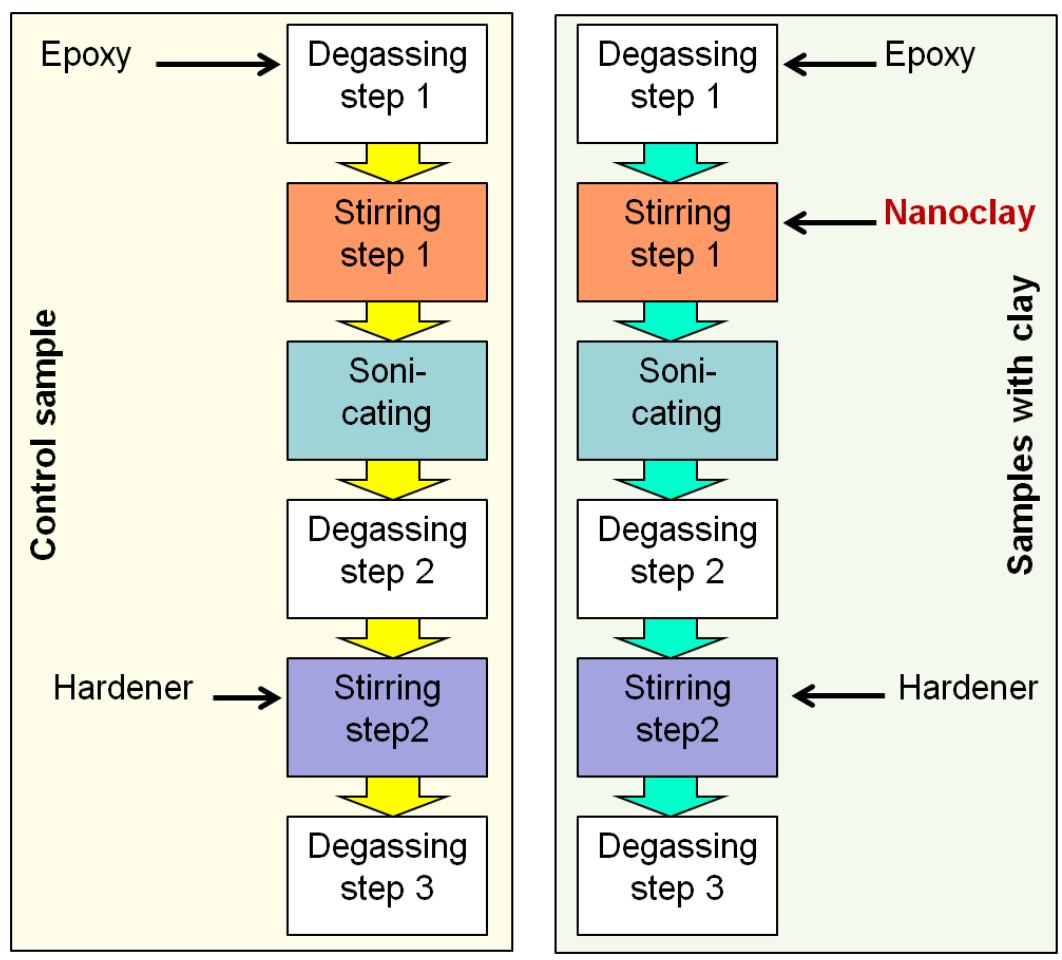

Figure 2. Schematic of the nanoclay dispersion process into the epoxy resin

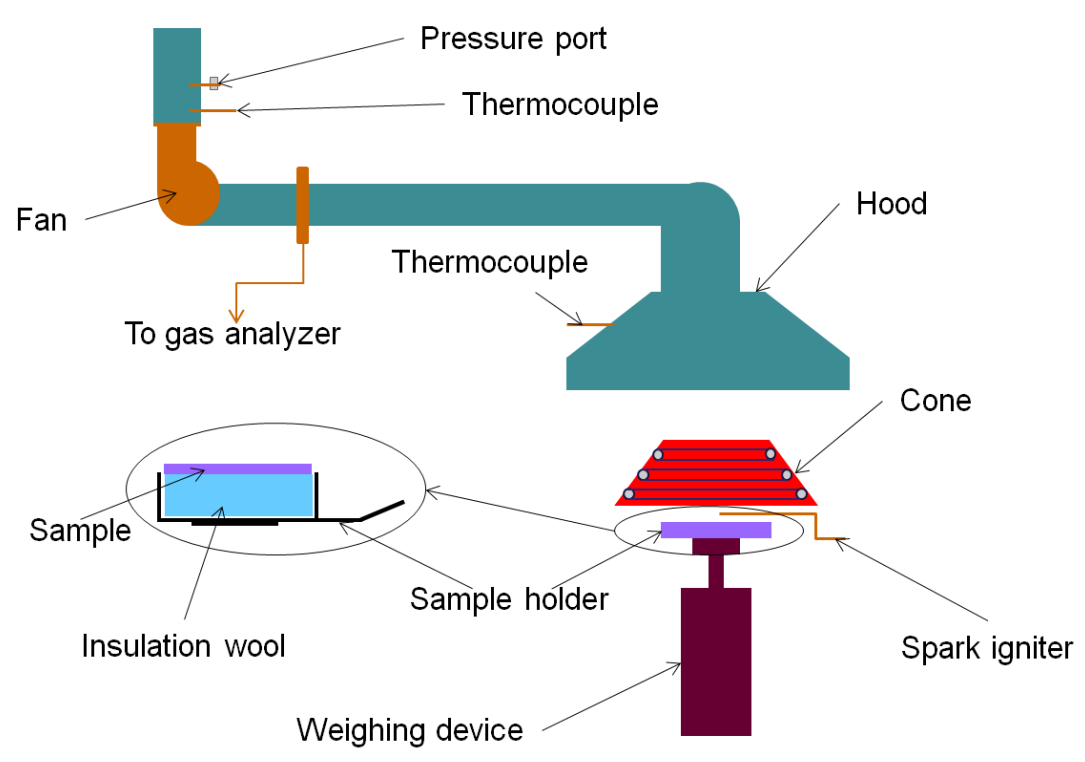

Figure 3. Schematic of the cone calorimeter test with the sample placed in the horizontal direction 


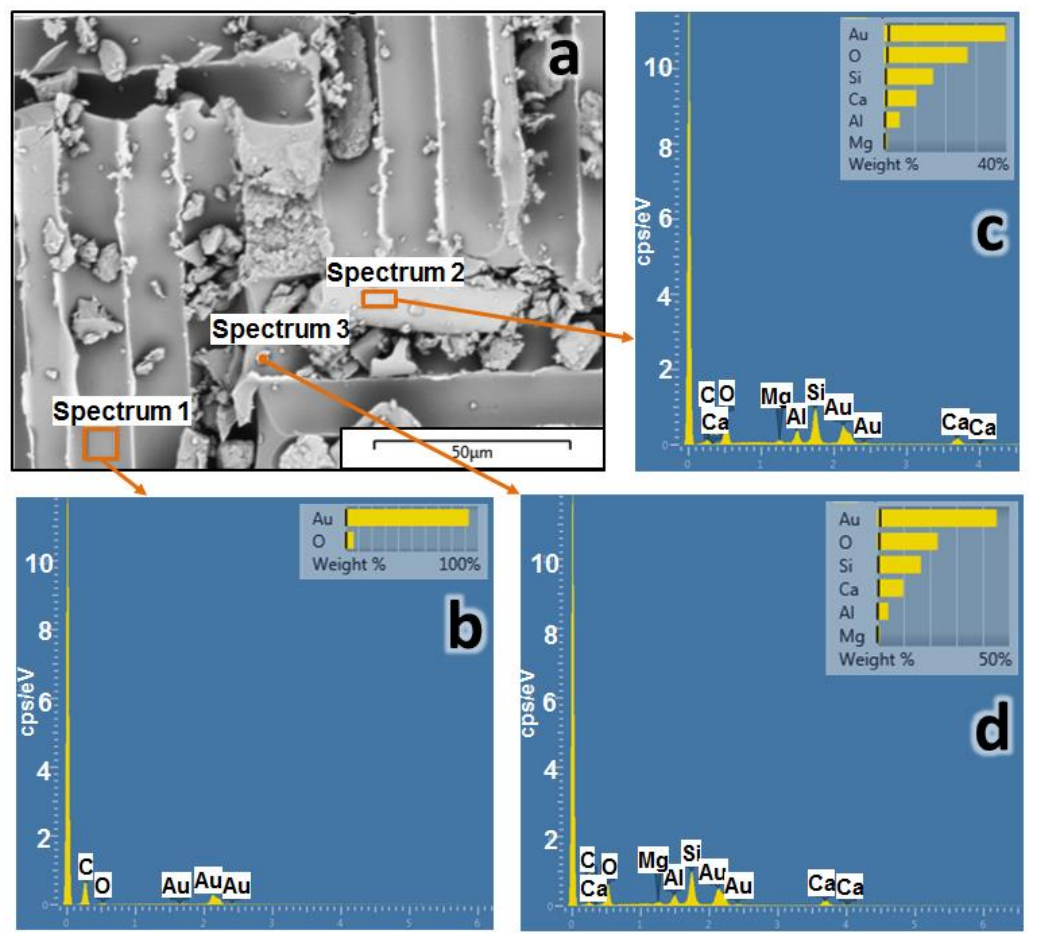

Figure 4. (a) SEM-EDS analysis of sample E3 with 3\% organoclay. Spectrums at different locations, representing: (b) epoxy resin, (c) $54 \mu \mathrm{m}$ tactoids, and (d) $4 \mu \mathrm{m}$ particles
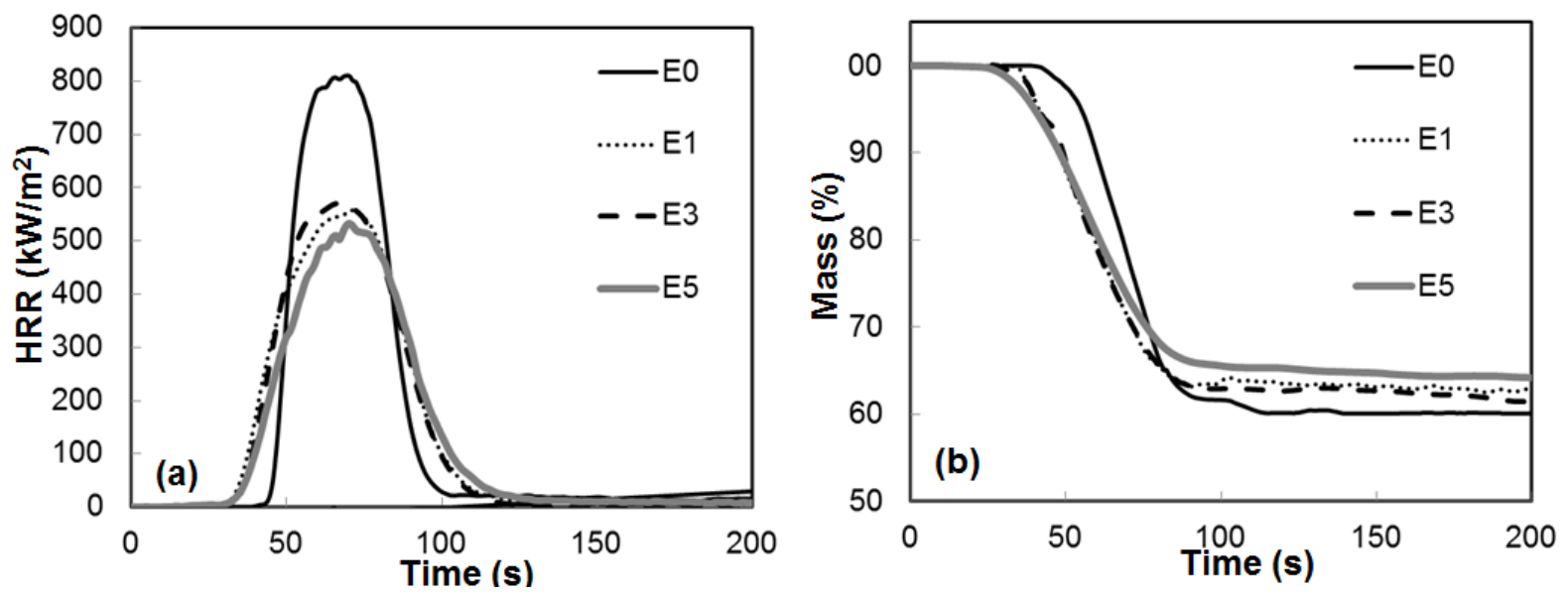

Figure 5. Time histories of: (a) heat release rate (HRR), and (b) mass changes of samples with no nanoclay, $1 \%, 3 \%$, and 5\% nanoclay (EO, E1, E3, and E5, respectively) exposed to $50 \mathrm{~kW} / \mathrm{m}^{2}$ heat flux in the cone calorimeter test 

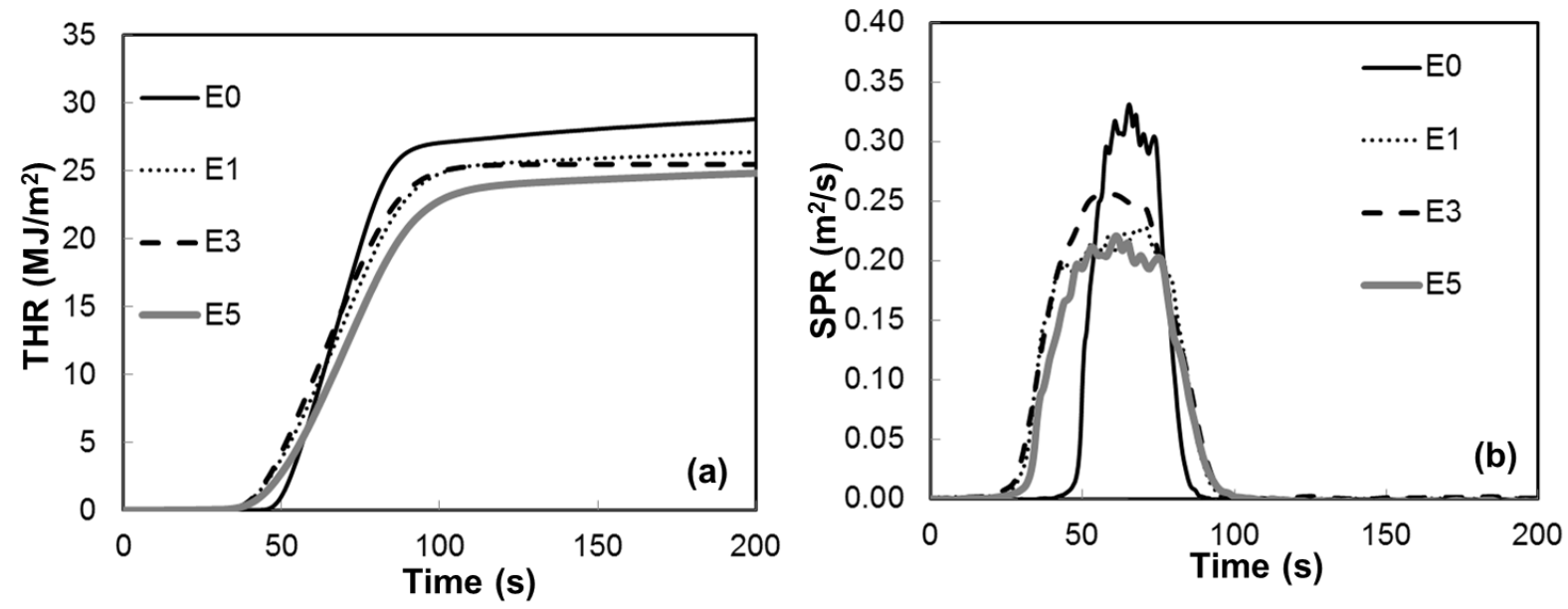

Figure 6. Time evolutions of: (a) total heat release, and (b) smoke production rate (SPR) of samples with no nanoclay, 1\%, 3\%, and 5\% nanoclay (E0, E1, E3, and E5, respectively) exposed to $50 \mathrm{~kW} / \mathrm{m}^{2}$ heat flux in the cone calorimeter test

E0
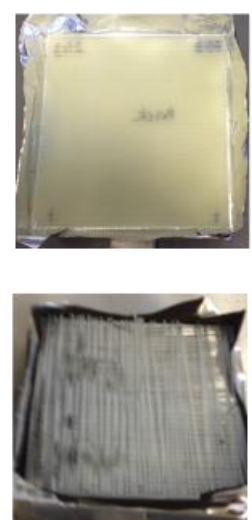

E1
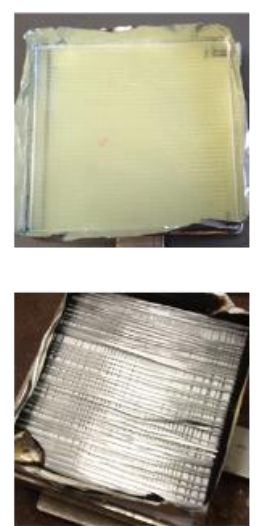

E3
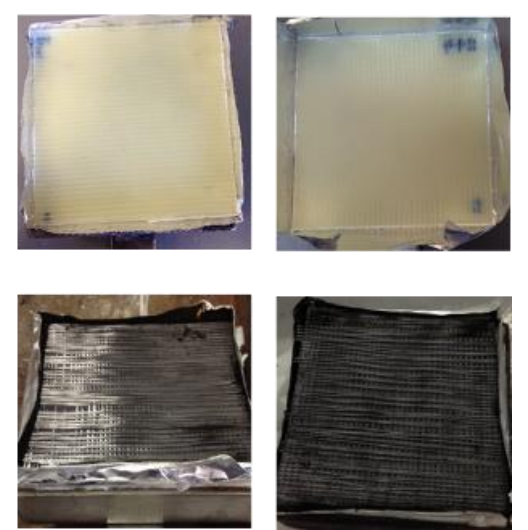

Figure 7. Images of samples before and after the cone calorimeter tests

E5

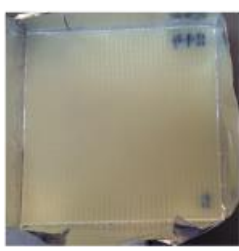



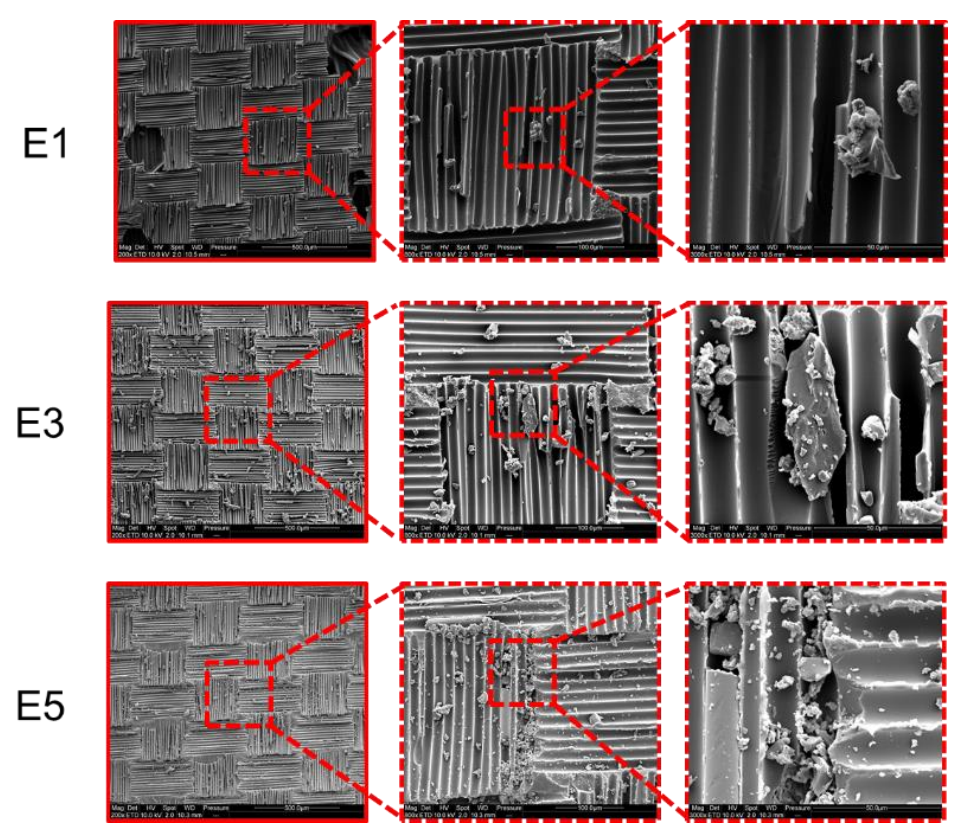

Figure 8. SEM images of E1, E3, and E5 samples at different magnifications: 200x, 800x and $3000 x$
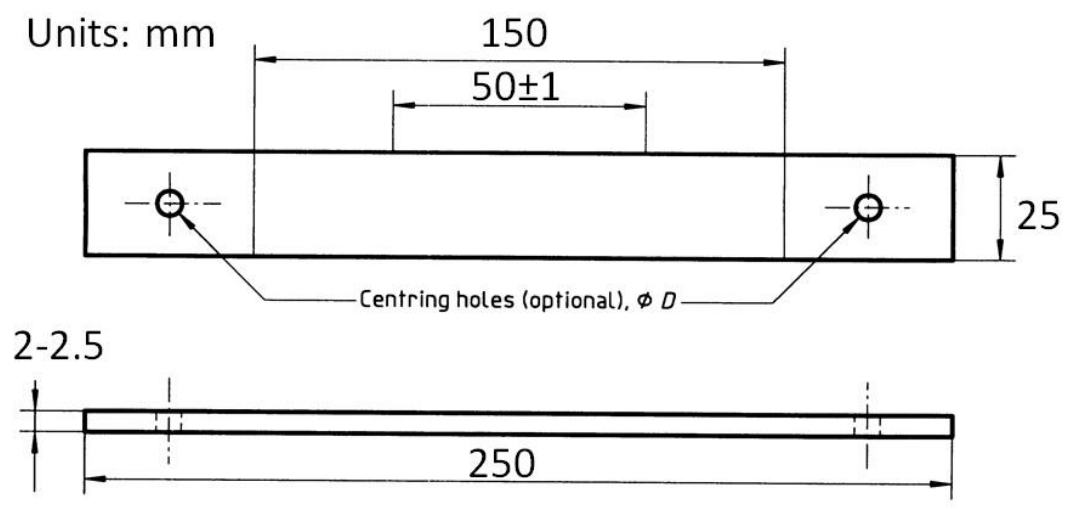

a) Type $\mathbf{2}$ specimen

Figure 9: Geometrical configurations of the type-2 composite sample for tensile testing according to the EN ISO 527-4.
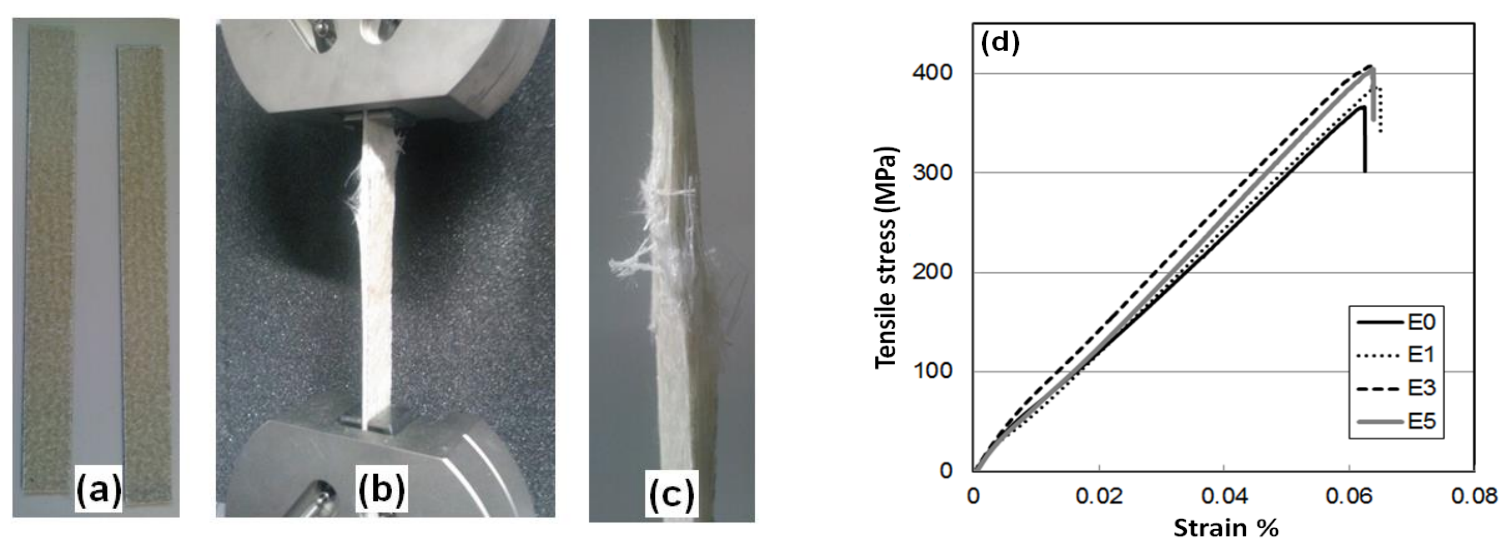

Figure 10: Tensile test results of nanoclay-enhanced GFRP. Samples (a) are prepared for tensile experiments $(b)$ and tested to failure (c). Representative stress-strain curves $(d)$ are presented for different clay contents. 
Table 1. Material compositions with varying nanoclay fraction

\begin{tabular}{ccc}
\hline Sample code & $\begin{array}{c}\text { Kinetix epoxy } \\
\text { wt.\% }\end{array}$ & $\begin{array}{c}\text { Nanoclay } \\
\text { wt.\% }\end{array}$ \\
\hline E0 & 100 & - \\
E1 & 99 & 1 \\
E3 & 97 & 3 \\
E5 & 95 & 5 \\
\hline
\end{tabular}

Table 2. Summary of experimental results reporting peaks of heat release rate (PHRR), required time to reach the PHRR $\left(T_{p}\right)$, carbon monoxide yield $\left(\mathrm{CO}_{y}\right)$ and carbon dioxide yield $\left(\mathrm{CO}_{2 y}\right)$

\begin{tabular}{cccccc}
\hline Sample & $\begin{array}{c}\text { PHRR } \\
\left(\mathrm{kW} / \mathrm{m}^{2}\right)\end{array}$ & $\mathbf{T}_{\mathbf{p}}$ (seconds) & $\begin{array}{c}\text { PHRR/T } \\
\left(\mathrm{kW} / \mathrm{m}^{2} \mathrm{~s}\right)\end{array}$ & $\mathbf{C O}_{\mathbf{y}}(\mathrm{kg} / \mathrm{kg})$ & $\begin{array}{c}\mathbf{C O}_{2 \mathbf{y}} \\
(\mathrm{kg} / \mathrm{kg})\end{array}$ \\
E0 & 818 & 64 & 12.78 & $\mathbf{0 . 0 6 4 8}$ & $\mathbf{2 . 4 2}$ \\
E1 & 558 & 71 & 7.85 & $\mathbf{0 . 0 8 6 5}$ & $\mathbf{2 . 3 9}$ \\
E3 & 570 & 66 & 8.64 & $\mathbf{0 . 0 8 2 2}$ & $\mathbf{1 . 7 2}$ \\
E5 & 533 & 71 & 7.50 & $\mathbf{0 . 0 9 2 1}$ & $\mathbf{1 . 6 9}$ \\
\hline
\end{tabular}

Table 3. Comparisons of the total heat release (THR), heat of combustion and total smoke production (TSP) for four samples with varying nanoclay fraction

\begin{tabular}{cccccc}
\hline Sample & $\begin{array}{c}\text { THR } \\
\left(\mathrm{MJ} / \mathrm{m}^{2}\right)\end{array}$ & $\begin{array}{c}\text { Heat of } \\
\text { combustion } \\
(\mathrm{MJ} / \mathrm{kg})\end{array}$ & $\begin{array}{c}\text { TSP } \\
\left(\mathbf{m}^{2}\right)\end{array}$ & $\begin{array}{c}\text { Laminate } \\
\text { thickness } \\
(\mathrm{mm})\end{array}$ & $\begin{array}{c}\text { Resin infusion } \\
\text { time } \\
(\mathrm{s})\end{array}$ \\
E0 & 28.83 & 31.50 & $\mathbf{1 0 . 4 6}$ & 2.45 & 93 \\
E1 & 26.42 & 25.12 & $\mathbf{8 . 8 8}$ & 2.51 & 131 \\
E3 & 25.48 & 20.80 & $\mathbf{1 0 . 0 1}$ & 2.63 & 269 \\
E5 & 24.83 & 18.98 & $\mathbf{8 . 1 8}$ & 2.64 & 272 \\
\hline
\end{tabular}

\begin{tabular}{|c|c|c|c|c|}
\hline $\begin{array}{l}\text { Nanoclay } \\
\text { Percentage }\end{array}$ & & $\begin{array}{c}\text { Tensile Strength } \\
(\mathrm{MPa})\end{array}$ & Maximum strain & Elastic Modulus (GPa) \\
\hline \multirow{2}{*}{$0 \%$} & Mean & 366 & $6.24 \%$ & 5.79 \\
\hline & SD & 17 & $0.43 \%$ & 0.19 \\
\hline \multirow{2}{*}{$1 \%$} & Mean & 387 & $6.49 \%$ & 6.16 \\
\hline & $\mathrm{SD}$ & 18 & $0.33 \%$ & 0.08 \\
\hline \multirow{2}{*}{$3 \%$} & Mean & 408 & $6.24 \%$ & 6.30 \\
\hline & $\mathrm{SD}$ & 6 & $0.28 \%$ & 0.01 \\
\hline \multirow{2}{*}{$5 \%$} & Mean & 405 & $6.38 \%$ & 6.10 \\
\hline & $\mathrm{SD}$ & 14 & $0.27 \%$ & 0.07 \\
\hline
\end{tabular}

\section{REFERENCES}

1. Crossley, R., P. Schubel, and A. Stevenson, Furan matrix and flax fibre as a sustainable renewable composite: Mechanical and fire-resistant properties in comparison to phenol, 
epoxy and polyester. Journal of Reinforced Plastics and Composites, 2014. 33(1): p. 5868.

2. Duflou, J.R., Y. Deng, K. Van Acker, and W. Dewulf, Do fiber-reinforced polymer composites provide environmentally benign alternatives? A life-cycle-assessment-based study. MRS Bulletin, 2012. 37(4): p. 374-382.

3. Nguyen, Q.T., T.D. Ngo, P. Mendis, and P. Tran, Composite Materials for the Next Generation Building Facade Systems. Civil Engineering and Architecture, 2013. 1(3): p. 88-95.

4. Pendhari, S.S., T. Kant, and Y.M. Desai, Application of polymer composites in civil construction: A general review. Composite Structures, 2008. 84(2): p. 114-124.

5. Faruqi, M.A., G. Escobedo, D. Sun, and J. Sai, Research and design guidelines for the construction of fiber-reinforced polymer reinforced concrete structures under fire exposure: A brief review. Journal of Reinforced Plastics and Composites, 2013. 32(17): p. 1302-1309.

6. Gibson, A.G., P.N.H. Wright, Y.S. Wu, A.P. Mouritz, Z. Mathys, and C.P. Gardiner, The integrity of polymer composites during and after fire. Journal of Composite Materials, 2004. 38(15): p. 1283-1307.

7. Katancic, Z., L.K. Krehula, A.P. Sirocic, V. Grozdanic, and Z. Hrnjak-Murgic, Effect of modified nanofillers on fire retarded high-density polyethylene/wood composites. Journal of Composite Materials, 2014. 48(30): p. 3771-3783.

8. Wei, X.D., A. de Vaucorbeil, P. Tran, and H.D. Espinosa, A new rate-dependent unidirectional composite model - Application to panels subjected to underwater blast. Journal of the Mechanics and Physics of Solids, 2013. 61(6): p. 1305-1318.

9. Liu, Y., C.L. Deng, J. Zhao, J.S. Wang, L. Chen, and Y.Z. Wang, An efficiently halogenfree flame-retardant long-glass-fiber-reinforced polypropylene system. Polymer Degradation and Stability, 2011. 96(3): p. 363-370.

10. Nguyen, Q.T., T.D. Ngo, P. Tran, P. Mendis, and D. Bhattacharyya, Influences of clay and manufacturing on fire resistance of organoclay/thermoset nanocomposites. Composites Part A: Applied Science and Manufacturing, 2015. 74: p. 26-37.

11. Nguyen, Q.T., P. Tran, T.D. Ngo, P.A. Tran, and P. Mendis, Experimental and computational investigations on fire resistance of GFRP composite for building facade. Composites Part B-Engineering, 2014. 62: p. 218-229.

12. Al-Saidy, A.H., F.W. Klaiber, and T.J. Wipf, Strengthening of steel-concrete composite girders using carbon fiber reinforced polymer plates. Construction and Building Materials, 2007. 21(2): p. 295-302.

13. Feo, L., A.S. Mosallam, and R. Penna, Mechanical behavior of web-flange junctions of thin-walled pultruded I-profiles: An experimental and numerical evaluation. Composites Part B: Engineering, 2013. 48(0): p. 18-39.

14. Uomoto, T., H. Mutsuyoshi, F. Katsuki, and S. Misra, Use of fiber reinforced polymer composites as reinforcing material for concrete. Journal of Materials in Civil Engineering, 2002. 14(3): p. 191-209.

15. Ghazlan, A., T.D. Ngo, and P. Tran, Influence of interfacial geometry on the energy absorption capacity and load sharing mechanisms of nacreous composite shells. Composite Structures, 2015. 132(0): p. 299-309.

16. Tran, P., T.D. Ngo, and P. Mendis, Bio-inspired composite structures subjected to underwater impulsive loading. Computational Materials Science, 2014. 82: p. 134-139.

17. Yang, C., P. Tran, T. Ngo, P. Mendis, and W. Humphries, Effect of Textile Architecture on Energy Absorption of Woven Fabrics Subjected to Ballistic Impact. Applied Mechanics and Materials, 2014. 553: p. 757-762. 
18. Dahiya, J.B., B.K. Kandola, A. Sitpalan, and A.R. Horrocks, Effects of nanoparticles on the flame retardancy of the ammonium sulphamate-dipentaerythritol flame-retardant system in polyamide 6. Polymers for Advanced Technologies, 2013. 24(4): p. 398-406.

19. Huang, G.B., J.G. Yang, X. Wang, and J.R. Gao, Nanoclay, intumescent flame retardants, and their combination with chemical modification for the improvement of the flame retardant properties of polymer nanocomposites. Macromolecular Research, 2013. 21(1): p. 27-34.

20. Thirumal, M., D. Khastgir, N.K. Singha, B.S. Manjunath, and Y.P. Naik, Effect of a Nanoclay on the Mechanical, Thermal and Flame Retardant Properties of Rigid Polyurethane Foam. Journal of Macromolecular Science Part a-Pure and Applied Chemistry, 2009. 46(7): p. 704-712.

21. Beyer, G., Flame Retardancy of Nanocomposites - from Research to Technical Products. Journal of Fire Sciences, 2005. 23(1): p. 75-87.

22. Dabrowski, F., M. Le Bras, R. Delobel, J.W. Gilman, and T. Kashiwagi, Using clay in PA-based intumescent formulations. Fire performance and kinetic parameters. Macromolecular Symposia, 2003. 194(1): p. 201-206.

23. Gilman, J.W., Flammability and thermal stability studies of polymer layered-silicate (clay) nanocomposites1. Applied Clay Science, 1999. 15(1-2): p. 31-49.

24. Gilman, J.W., S. Lomakin, T. Kashiwagi, D.L. VanderHart, and V. Nagy, Characterization of flame-retarded polymer combustion chars by solid-state 13C and 29Si NMR and EPR. Fire and Materials, 1998. 22(2): p. 61-67.

25. Gilman, J.W., S.J. Ritchie, T. Kashiwagi, and S.M. Lomakin, Fire-retardant additives for polymeric materials-I. Char formation from silica gel-potassium carbonate. Fire and Materials, 1997. 21(1): p. 23-32.

26. Liu, T., K. Ping Lim, W. Chauhari Tjiu, K.P. Pramoda, and Z.-K. Chen, Preparation and characterization of nylon 11/organoclay nanocomposites. Polymer, 2003. 44(12): p. 35293535 .

27. Morgan, A.B., Flame retarded polymer layered silicate nanocomposites: a review of commercial and open literature systems. Polymers for Advanced Technologies, 2006. 17(4): p. 206-217.

28. Morgan, A.B., R.H. Harris, T. Kashiwagi, L.J. Chyall, and J.W. Gilman, Flammability of polystyrene layered silicate (clay) nanocomposites: Carbonaceous char formation. Fire and Materials, 2002. 26(6): p. 247-253.

29. Shi, Y., T. Kashiwagi, R.N. Walters, J.W. Gilman, R.E. Lyon, and D.Y. Sogah, Ethylene vinyl acetate/layered silicate nanocomposites prepared by a surfactant-free method: Enhanced flame retardant and mechanical properties. Polymer, 2009. 50(15): p. 34783487.

30. Shi, L. and M.Y.L. Chew, Fire behaviors of polymers under autoignition conditions in a cone calorimeter. Fire Safety Journal, 2013. 61(0): p. 243-253.

31. Gintert, M.J., S.C. Jana, and S.G. Miller, A novel strategy for nanoclay exfoliation in thermoset polyimide nanocomposite systems. Polymer, 2007. 48(14): p. 4166-4173. 


\section{University Library}

\section{- M M N E R VA A gateway to Melbourne's research publications}

Minerva Access is the Institutional Repository of The University of Melbourne

Author/s:

Ngo, TD;Nguyen, QT;Nguyen, TP;Tran, P

Title:

Effect of Nanoclay on Thermomechanical Properties of Epoxy/Glass Fibre Composites

Date:

2016-04-01

Citation:

Ngo, T. D., Nguyen, Q. T., Nguyen, T. P. \& Tran, P. (2016). Effect of Nanoclay on

Thermomechanical Properties of Epoxy/Glass Fibre Composites. ARABIAN JOURNAL FOR SCIENCE AND ENGINEERING, 41 (4), pp.1251-1261. https://doi.org/10.1007/ s13369-015-1898-0.

Persistent Link:

http://hdl.handle.net/11343/283113 